\title{
Alterations on monoamines concentration in rat hippocampus produced by lipoic acid
}

\author{
Ítala Mônica de Sales Santos', Rizângela Lyne Mendes de Freitas², \\ Gláucio Barros Saldanha², Adriana da Rocha Tomé ${ }^{3}$ \\ Joaquín Jordán ${ }^{4}$, Rivelilson Mendes de Freitas ${ }^{1}$
}

\begin{abstract}
The purposes of the present study were to verify monoamines (dopamine (DA), norepinephrine $(\mathrm{NE})$, serotonin (5-HT)), and their metabolites (3,4-hydroxyphenylacetic acid (DOPAC), homovanillic acid (HVA) and 5-hydroxyindoleacetic acid (5-HIAA)) contents in rat hippocampus after lipoic acid (LA) administration. Wistar rats were treated with $0.9 \%$ saline (i.p., control group) and LA (10, 20 or 30 mg/kg, i.p., LA10, LA20 and LA30 groups, respectively). After the treatments all groups were observed for $24 \mathrm{~h}$. The NE and DA levels were increased only in $20 \mathrm{mg} / \mathrm{kg}$ dose of LA in rat hippocampus. Serotonin content and in their metabolite 5-HIAA levels was decreased in same dose of LA. On the other hand, in DOPAC and HVA levels did not show any significant change. The alterations in hippocampal monoamines can be suggested as a possible of brain mechanism of action from this antioxidant. The outcome of the study may have therapeutic implications in the treatment of neurodegenerative diseases. Key words: lipoic acid, hippocampus, dopamine, norepinephrine, serotonin.
\end{abstract}

\section{Alterações na concentração de monoaminas no hipocampo de ratos produzidas pelo ácido lipóico}

\section{RESUMO}

O objetivo do presente estudo foi verificar a concentração das monoaminas (dopamina (DA), norepinefrina (NA), serotonina (5-HT)), e seus metabólitos (ácido 3,4-hidroxifenil (DOPAC), ácido homovanílico (HVA) e 5 ácido hydroxiindolacético (5-HIAA)) no hipocampo de ratos após administração do ácido lipóico (AL). Ratos Wistar foram tratados com solução salina 0,9\% (i.p., grupo controle) e AL (10, 20 ou 30 mg/kg, i.p., AL10, AL20 e AL30 grupos, respectivamente). Após os tratamentos todos os grupos foram observados durante $24 \mathrm{~h}$. $\mathrm{O}$ conteúdo de DA no hipocampo de ratos foi aumentado apenas com AL na dose de $20 \mathrm{mg} /$ $\mathrm{kg}$ dose. A concentração de serotonina e do seu metabólito 5-HIAA também foi diminuída com esta dose de AL. Por outro lado, os níveis de DOPAC e de HVA não mostrram nenhuma mudança significativa. As alterações na concentração das monoaminas hipocampais podem ser sugeridas como um possível mecanismo de ação cerebral deste antioxidante. O resultado do estudo pode ter implicações terapêuticas no tratamento de doenças neurodegenerativas.

\section{Correspondence}

Rivelilson Mendes de Freitas

Rua Cícero Eduardo s/n

64600-000 Picos PI - Brasil

E-mail: rivelilson@ufpi.br

\section{Support \\ This study was supported in part by grants from the Brazilian National Research Council (CNPq), Brazil. I.M.S.S. and R.M.F are fellows from CNPq}

Received 15 September 2009 Received in final form 23 October 2009 Accepted 4 November 2009

Palavras-chave: ácido lipóico, hipocampo, dopamina, norepinefrina, serotonina.

Alpha-lipoic acid (LA) also known as thioctic acid contains two thiol groups, which may be oxidized or reduced ${ }^{1}$ (Fig 1). As the thiol antioxidant glutathione, LA is part of a redox pair, being the oxidized partner of dihydrolipoic acid (DHLA), the reduced form. Unlike glutathione reduced which only the reduced form is an antioxi- 


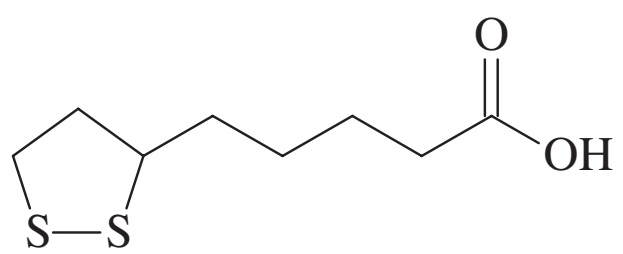

Fig 1. $\alpha$-lipoic acid structure (6,8-dithio-octanoic acid).

dant, both the oxidized and reduced forms of LA are antioxidants. LA is 6,8-dithio-octanoic acid, an eight-carbon disulphide containing a single chiral center. LA also contains an asymmetric carbon, thus resulting in two possible optical isomers. Only the R-isomer is endogenously synthesized. Both isomers seem to have different potencies; it was previously shown that the R-form is more potent than the $\mathrm{S}$-form in its ability to stimulate glucose uptake $^{2}$, as well as to increase insulin-stimulated glucose uptake in rats $^{3}$. On the other hand, the S-form exerts a slightly increased affinity for glutathione reductase.

LA is a naturally occurring compound that is synthesized in small amounts by plants and animals, including humans ${ }^{4,5}$. Endogenously synthesized LA is covalently bound to specific proteins, which function as cofactors for mitochondrial dehydrogenase enzyme complexes. In addition, to the physiological functions of protein-bound LA, there is an increasing scientific and medical interest in potential therapeutic uses ${ }^{6}$.

According to Packer and colleagues, an ideal therapeutic antioxidant should fulfill several criteria. These include absorption from the diet, conversion in cells and tissues into usable form, the presence of variety antioxidant actions in both membrane and aqueous phases, and low toxicity ${ }^{7}$. LA is unique among natural antioxidants in its ability to fulfill all of these requirements, making it a potentially highly effective therapeutic agent for a number of conditions in which oxidative damage has been implicated. LA's antioxidant properties consist of the following: [1] its capacity to directly scavenge reactive oxygen species (ROS); [2] its ability to regenerate endogenous antioxidants, such as glutathione reduced, vitamins $\mathrm{E}$ and $\mathrm{C}$; and [3] its metal chelating activity, resulting in reduced ROS production.

LA has a long-established efficacy in slow-onset and long-term reduction of oxidative processes involved in the pathogenesis of neurodegenerative diseases ${ }^{8,9}$. Although the effect was slow, drug's cheapness, low toxicity and the ability to ameliorate other unpleasant side effects of these distressing conditions make it a practical choice ${ }^{10}$. Protecting the central nervous system (CNS) against oxidative damage may be a useful therapeutic approach. Thus, LA may possess a modulatory role in the treatment of neurodegenerative diseases, since this com- pound interrupts cellular oxidative processes in both its oxidized and reduced forms. The effects of LA in the central nervous system (CNS) have not yet been determined, therefore, would be important to conduct these studies to clarify its brain mechanism of action.

Dopamine (DA), serotonin (5-HT), norepinephrine (NE) and their metabolites 3,4-hydroxyphenylacetic acid (DOPAC), homovanillic acid (HVA) and 5-hydroxyindoleacetic acid (5-HIAA), represent the most important monoamines and metabolites-derived neurotransmitters. DA and NE are the most abundant excitatory monoamines neurotransmitter and are widely distributed in the mammalian brain, including the hippocampus ${ }^{11}$. DA is present at all parts of the CNS, at higher concentration in the substantia nigra and globus pallidus, followed by hypothalamus and hippocampus. There are some diseases associated with changes in these neurotransmitters levels. A role for the disrupted dopaminergic transmission in the etiology of chronic neurodegenerative diseases was postulated $^{8,12}$. Pharmacological studies with LA can revealed their effects in monoamines concentrations, since when established may justify the use of this antioxidant in the clinic treatment of neurodegenerative diseases.

Previous studies in our laboratory ${ }^{8,9}$ have shown anticonvulsant and neuroprotective activities of LA in pilocarpine model. Thus, the pharmacological acknowledgement of LA at the level of CNS should be considered of great importance.

In this way, the purposes of the present work were to verify monoamines and their metabolites contents in rat hippocampus after LA administration, and to identify its possible mechanism of action at the CNS level.

\section{METHOD}

In each experiment, male Wistar rats weighing (250$280 \mathrm{~g})$ provided by the Animal House of the Federal University of Piaui (Brazil) were used. The animals were housed in groups of 30, into plastic cages with sawdust as beddings, and kept in a room with controlled temperature $\left(26 \pm 1^{\circ} \mathrm{C}\right)$ and a 12-h light/dark cycle, with food and water ad libitum, except during the experiments. The animals were treated in accordance to the current law and the NIH Guide for Care and Use of Laboratory Animals. The project was previously submitted to Animal's Ethics Committee of the Federal University of Piaui.

Animals were treated with $0.9 \%$ saline (controls) and lipoic acid at the doses of 10, 20 or $30 \mathrm{mg} / \mathrm{kg}$, i.p. (LA10, LA20 or LA30 groups, respectively). Twenty-four hours after the drug administration, the animals were sacrificed by decapitation, and the hippocampus was dissected. After dissection, the area was used for monoamines and metabolites determinations ${ }^{13}$.

Analyses of monoamines and metabolites were car- 
ried out with a high-performance liquid chromatography (HPLC, Shimadzu, Japan) apparatus. For all the experimental procedures, $10 \%(\mathrm{w} / \mathrm{v})$ homogenates of hippocampus of the LA10 $(n=7)$, LA20 $(n=7)$, LA30 $(n=7)$ and control $(n=9)$ groups were prepared. The endogenous levels of DA, NE, 5-HT and their non conjugated metabolites DOPAC, HVA, and 5-HIAA were determined by reverse-phase high-performance liquid chromatography (HPLC) with electrochemical detection. Briefly, a C18 reverse phase column (Shim-pack, CLC-ODS $150 \mathrm{~mm} \times 4.6$ $\mathrm{mm}$; Shimadzu, Kyoto, Japan), an amperometric detector (Shimadzu, LECD-6A) and a liquid chromatography work station were used. The hippocampus was immediately homogenized in $0.2 \mathrm{M}$ perchloric acid. The homogenates $10 \%(\mathrm{w} / \mathrm{v})$ were centrifuged $(20.000 \times \mathrm{g}$ per min for $30 \mathrm{~min}$ ). After centrifugation $20 \mu \mathrm{l}$ of the supernatant was injected into the chromatograph. The mobile phase $(\mathrm{pH}$ 3.0) used at a flow rate of $0.6 \mathrm{ml} / \mathrm{min}$ was of the following composition: $15.7 \mathrm{~g}$ of citric acid, $471.5 \mathrm{ml}$ of twice-distilled water, $\mathrm{NaOH}$ sufficient to bring $\mathrm{pH}$ to $7.0,3.78 \mathrm{mg}$ of octyl sodium sulfate, $20 \mathrm{ml}$ of acetonitrile and $10 \mathrm{ml}$ of tetrahydrofuran. Oxidation potential was fixed at 0.85 $\mathrm{V}$ using a glass carbon working versus an $\mathrm{Ag} / \mathrm{AgCl}$ reference electrode. The peak areas of the external standards were used to quantify the sample peaks. The values obtained were expressed as ng/g wet tissue.

All results are presented as mean \pm S.E.M of number of animals used in experiments. The results were compared using ANOVA followed by Student-Newman-Keuls test. The significance level was set at $\mathrm{p}<0.05$.

\section{RESULTS}

DA levels in rat hippocampus increased by $9 \%$ after LA administration $(20 \mathrm{mg} / \mathrm{kg})$, when compared to the controls $(p<0.0001)$. No significant changes were observed in DA levels after LA treatment (10 or $30 \mathrm{mg} / \mathrm{kg}$, i.p.), when compared to control group (Fig 2). When dopamine level at LA20 group was compared to the LA10 group a significant increase (11\%) was also found. In addition, when dopamine level at LA30 group was compared to the LA20 group a significant decrease (10\%) was also found ( $\mathrm{p}<0.0489$ ). No significant changes were observed in DOPAC and HVA levels in rat hippocampus, after the administration of LA (10, 20 or $30 \mathrm{mg} / \mathrm{kg}$ i.p.) when compared to the control (Fig 2).

NE level in rat hippocampus increased by $11 \%$ after LA administration $(20 \mathrm{mg} / \mathrm{kg})$ as compared to controls ( $\mathrm{p}<0.0001)$. At LA20 group, 5 -HT level decreased by $9 \%(\mathrm{p}<0.0345)$ and 5 -HIAA level decreased by $21 \%$ $(\mathrm{p}<0.0001)$ after LA treatment, compared to the controls. No significant changes were observed in NE, 5-HT and 5-HIAA levels in rat hippocampus, after the administration of LA (10 or $30 \mathrm{mg} / \mathrm{kg}$, i.p.) when compared to

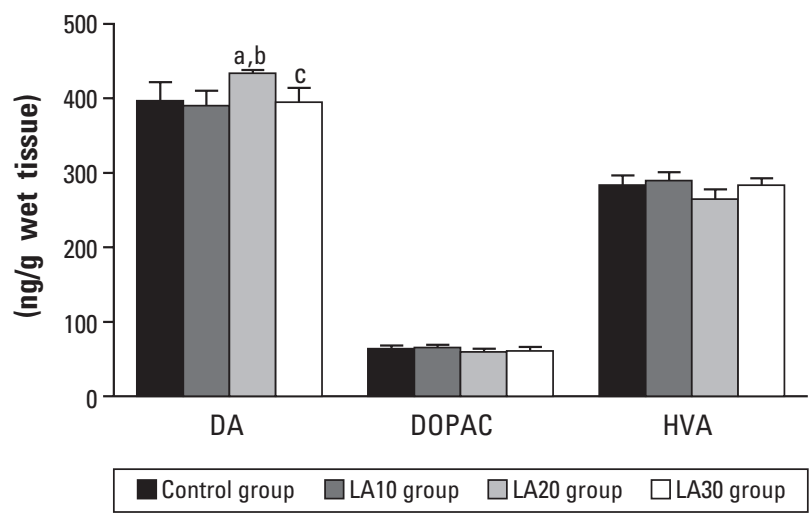

Fig 2. Effects of lipoic acid on dopamine (DA), and their metabolites (3,4-hydroxyphenylacetic acid (DOPAC), and homovanillic acid (HVA) in rat hippocampus. ${ }^{a} \mathrm{p}<0.05$ as compared to control (ANOVA and Student-Newman-Keuls test); ${ }^{b} p<0.05$ as compared to LA10 group (ANOVA and Student-Newman-Keuls test); ${ }^{c} p<0.05$ as compared to LA20 group (ANOVA and Student-Newman-Keuls test).

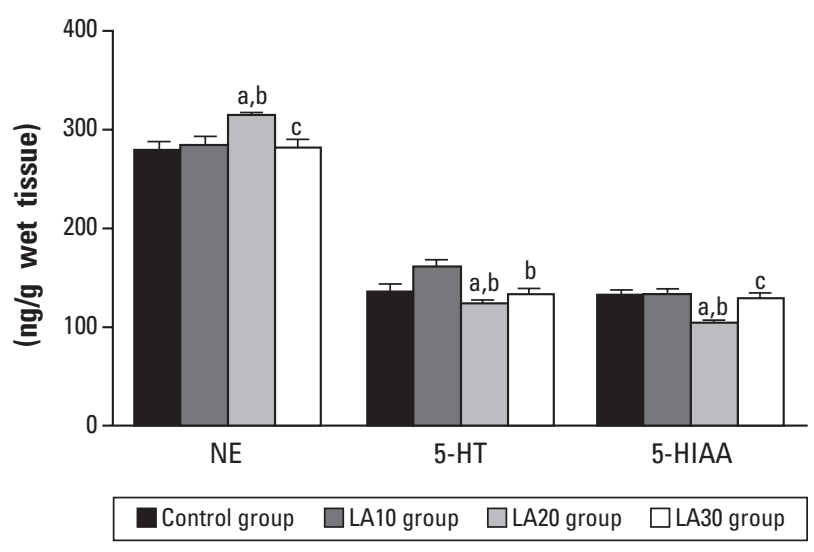

Fig 3. Effects of lipoic acid on norepinephrine (NE), serotonin (5-HT) and and their metabolite 5-hydroxyindoleacetic acid (5-HIAA) levels in rat hippocampus. ${ }^{a} \mathrm{p}<0.05$ as compared to control (ANOVA and Student-Newman-Keuls test); ${ }^{b} p<0.05$ as compared to LA10 group (ANOVA and Student-Newman-Keuls test); ${ }^{c} p<0.05$ as compared to LA20 group (ANOVA and Student-Newman-Keuls test).

the control (Fig 3). When NE level at LA20 group was compared to the LA10 group a significant increase (13\%) $(\mathrm{p}<0.0121)$ was found, instead 5-HT and 5HIAA levels decreased by $12 \%(\mathrm{p}<0.0006)$ and $20 \%(\mathrm{p}<0.0004)$ compared to LA10 group, respectively. In addition, when NE level at LA30 group was compared to the LA20 group a significant decrease $(11 \%)(\mathrm{p}<0.0049)$ was found, instead 5HIAA levels increased by $13 \%(\mathrm{p}<0.0014)$ compared to LA20 group (Fig 3).

\section{DISCUSSION}

Most of the studies with LA were carried out in organs and systems other than the $\mathrm{CNS}^{14}$. In the present 
work, DA, NE, 5-HT and their non conjugated metabolites DOPAC, HVA, and 5-HIAA levels were determined in rat hippocampus, after the LA administration. In the present study after the LA acute administration $(20 \mathrm{mg} /$ $\mathrm{kg}$ ), DA and NE levels were increased in rat hippocampus. In a previous study, we observed that LA in same dose increased the locomotor activity, in the open field test, confirming that LA do not posses inhibitory effect and the behavior presented may be related to changes in these monoamines concentrations in the hippocampus (data not show). Recently, Meurs and colleagues ${ }^{15}$, described an increase in hippocampal DA content in the establishment of neurodegenerative diseases. DA has a modulatory effect on the dopaminergic system, in which increase of DA in the hippocampus is correlated with decreased glutamate levels. Dopamine modulates fast excitatory synaptic transmission in several brain regions. Early studies in the hippocampus revealed that DA, in particular via $D_{2}$ receptors, indirectly stimulates $Y_{2}$ receptor causing inhibition of glutamatergic system ${ }^{15}$. These results suggest that LA probably exert their effects in CNS through of indirect stimulation of $Y_{2}$ receptor, since, that produces an increase in DA levels.

The result suggests that the observed increase in dopamine level was not produced by the activation of the sparse dopaminergic projection from ventral tegmental area to the hippocampus ${ }^{16}$, this increase was probably produced by inhibition of glutamatergic system by LA. Furthermore, we suggest that the increased dopamine and norepinephrine levels can be produced by three mechanisms: [1] by increasing their synthesis and or release; [2] by reduction in their metabolization rate; and/or [3] by decreasing its reuptake brain. In another set of experiments previous study showed that ventral tegmental area stimulation releases endogenous dopamine from the axonal terminals of dopaminergic neurons in the accumbens, and our results suggest that LA induces the release of dopamine in hippocampus ${ }^{17,18}$.

The hippocampus is a region structurally and functionally affected in neurodegenerative diseases ${ }^{19,20}$. A reduced hippocampal volume has been reported in patients suffering from depression, but it is still unknown if these changes can be reversed by antioxidants treatment, being necessary more studies to clarify the antioxidant effects. Based in this, we also showed a decrease in 5-HT levels only after LA administration at the dose of $20 \mathrm{mg} /$ $\mathrm{kg}$. We believe that the LA dose-response curve in the hippocampus may be bell-shaped: at a low dose range, it increases 5-HT levels, decreasing them at higher doses. Therefore, it would be important to test the anxyolitic and/or antidepressant effects of LA, once, that changes in 5-HT content in hippocampus are detected in neurodegenerative disorders.
During chronic mild stress leads to altered synaptic function and cellular survival in the ventral hippocampus $^{21}$. These impairments of the hippocampus may be compatible with altered emotionality, cognitive impairment, social isolation and disturbed memory ${ }^{22}$. Acute antioxidant treatment can modified hippocampal serotonergic transmission. Serotonin is suggested to regulate aspects of the development and the plasticity of brain circuits. Serotonin and GABA show a reciprocal modulatory function in the hippocampus. This region is rich in both 5 -HT and GABA terminals and receptors ${ }^{23,24}$. Projections from serotonergic neurons of the raphe nuclei terminate on GABAergic hippocampal interneurons increasing or decreasing their activity via serotonergic receptors ${ }^{25,26}$. On the other hand, inhibition of the GABA receptor decreases hippocampal 5-HT level, while application of GABA agonists to hippocampus decreases 5-HT release ${ }^{24}$. This reciprocal modulation of 5-HT and GABA in the hippocampus appears incompatible with the simplistic hypotheses of decreased 5-HT and GABA levels in neurodegenerative diseases. Hence, the study of LA effects in hippocampus may be useful to study the respective contribution direct of serotonin and/or indirect of GABA in the treatment of CNS diseases. We suggest that the decreased in serotonin levels can be produced by three mechanisms: [1] by decreasing of their synthesis and/or release; [2] by elevation in their metabolization rate; and/ or [3] by increasing its reuptake brain. However, further studies should be performed to confirm the hypothesis of that LA exert effects in serotonin concentration.

In addition, the hippocampus is responsible for some aspects of the neurobiology of memory ${ }^{11}$, as the consolidation of memory. The selective activation of dopaminergic receptors, as well as serotonergic receptors, is followed by the sequential intervention of several metabolic pathways mediated by pre- and post-synaptic protein kinases that also activate proteins necessary to the formation of memory. In this case, we suggest that the LA can change the concentration of these, as well as can produce effects indirect on amino acids contents in the hippocampus. Therefore, further studies should be performed with LA, since these amino acids may interfere with various brain mechanisms, altering several neurotransmission systems and producing neurodegenerative diseases. Thus, more specific studies must be conducted in order to further clarify these questions.

This study showed, for the first time, the effects of LA on monoamines levels, in the CNS. In conclusion, our results are consistent with the hypothesis that LA stimulates the release and/or syntheses or reduces the metabolization rate of endogenous monoamines. This substance increased the dopamine and norepinephrine levels in rat hippocampus. Moreover, serotonin levels were decreased. 
Together, these results are of interest, considering that some neurodegenerative diseases are related to the imbalance of these monoamines levels in the CNS.

\section{ACKNOWLEDGMENTS - We would like to thank Stenio Gardel Maia} for her technical assistance.

\section{REFERENCES}

1. Packer L, Witt EH, Tritschler HJ. alpha-Lipoic acid as a biological antioxidant. Free Radic Biol Med 1995;19:227-250.

2. Estrada DE, Ewart HS, Tsakiridis T, et al. Stimulation of glucose uptake by the natural coenzyme alpha-lipoic acid/thioctic acid: participation of elements of the insulin signaling pathway. Diabetes 1996:45:1798-1804.

3. Khanna S, Roy S, Packer L, Sen CK. Cytokine-induced glucose uptake in skeletal muscle: redox regulation and the role of alpha-lipoic acid. Am J Physiol 1999;276:1327-1333.

4. Carreau JP. Biosynthesis of lipoic acid via unsaturated fatty acids. Methods Enzymol 1979;62:152-158.

5. Sik A, Penttonen M, Ylinen A, Buzsaki G. Hippocampal CA1 interneurons: an in vivo intracellular labeling study. J Neurosci 1995;15:6651-6665.

6. Kramer K, Packer L. R-alpha-lipoic acid. In: Kramer K, Hoppe P, Packer L (Eds). Nutraceuticals in Health and Disease Prevention. New York: Marcel Dekker, Inc; 2001:129-164.

7. McKittrick CR, Magarinos AM, Blanchard DC, Blanchard RJ, McEwen BS, Sakai RR. Chronic social stress reduces dendritic arbors in CA3 of hippocampus and decreases binding to serotonin transporter sites. Synapse 2000;36:85-94.

8. Freitas RM, The evaluation of effects of lipoic acid on the lipid peroxidation, nitrite formation and antioxidant enzymes in the hippocampus of rats after pilocarpine-induced seizures. Neurosci Lett 2009;45:140-144.

9. Militão GCG, Ferreira, PMP, Freitas RM. Effects of lipoic acid on oxidative stress in rat striatum after pilocarpine-induced seizures. Neurochem Int 2009; in press.

10. Gaspar P, Cases O, Maroteaux L. The developmental role of serotonin: news from mouse molecular genetics. Nat Rev Neurosci 2003:4:1002-1012.

11. Goodman and Gilman. As bases farmacológicas da terapêutica/editores responsáveis, In: Hardman JG, Limbird LE, Gilman AG (eds) (tradução da 10. ed. Original, Vorsatz CM, revisão técnica, Fonseca AL), McGraw-Hill, Rio de Janeiro, 2005;392:229-234

12. Smith AR, Shenvi SV, Widlansky M, Suh JH, Hagen TM. Lipoic acid as a poten- tial therapy for chronic diseases associated with oxidative stress. Curr Med Chem 2004;11:1135-1146.

13. Burke RE, Greenbaun D. Effect of post-mortem factors on muscarinic receptor subtypes in rat brain. J Neurochem 1987:49:529-596

14. Freitas RM, Nascimento VS, Sousa FCF, Vasconcelos SMM, Viana GSB, Fonteles MMF. Catalase activity in cerebellum, hippocampus, frontal cortex and striatum after status epilepticus induced by pilocarpine in Wistar rats. Neurosci Lett 2004;365:102-105.

15. Meurs A, Clinckers R, Ebinger G, Michotte Y, Smolders I. Sigma 1 receptor-mediated increase in hippocampal extracellular dopamine contributes to the mechanism of the anticonvulsant action of neuropeptide Y. Eur J Neurosci 2007;26:3079-3092.

16. Ishikawa K, Ott T, McGaugh JL, Evidence for dopamine as a transmitter in dorsal hippocampus. Brain Res 1982;232:222-226

17. Kebabian JW, Calne DB. Multiple receptors for dopamine. Nature 1979;277:93-96.

18. Tao R, Ma Z, Auerbach SB. Differential regulation of 5-hydroxytryptamine release by GABAA and GABAB receptors in midbrain raphe nuclei and forebrain of rats. Br J Pharmacol 1996;119:1375-1384.

19. Lopez JF, Vazquez DM, Chalmers DT, Watson SJ. Regulation of 5-HT receptors and the hypothalamic-pituitary-adrenal axis. Implications for the neurobiology of suicide. Ann NY Acad Sci 1997;836:106-134.

20. Summers TR, Matter JM, McKay JM, et al. Rapid glucocorticoid stimulation and GABAergic inhibition of hippocampal serotonergic response: In vivo dialysis in the lizard anolis carolinensis. Horm Behav 2003;43:245-253.

21. Jayatissa MN, Bisgaard C, Tingstrom A, Papp M, Wiborg O. Hippocampal cytogenesis correlates to escitalopram-mediated recovery in a chronic mild stress rat model of depression. Neuropsychopharmacology 2006;31:2395-2404.

22. Bartesaghi R. Effect of early isolation on the synaptic function in the dentate gyrus and field CA1 of the guinea pig. Hippocampus 2004;14:482-498

23. Sheline YI, Gado MH, Kraemer HC. Untreated depression and hippocampal volume loss. Am J Psychiatry 2003;160:1516-1518.

24. Stanzione P, Calabresi P, Mercuri N, Bemardi G. Dopamine modulates CA1 hippocampal neurones by elevating the threshold for spike generation: an in vitro study, Neuroscience 1984;13:1105-1116.

25. Halasy K, Miettinen R, Szabat E, Freund TF. GABAergic interneurons are the major postsynaptic targets of median raphe afferents in the rat dentate gyrus. Eur J Neurosci 1992;4:144-153.

26. Pick U, Haramaki N, Constantinescu A, Handelman GJ, Tritschler HJ, Packer L. Glutathione reductase and lipoamide dehydrogenase have opposite stereo specificities for alpha-lipoic acid enantiomers. Biochem Biophys Res Commun 1995;206:724-730. 